University of Nebraska - Lincoln

DigitalCommons@University of Nebraska - Lincoln

Faculty Publications, Department of Psychology

Psychology, Department of

May 2001

\title{
Multidisciplinarity and cognitive science
}

\author{
Barbara Von Eckardt \\ University of Nebraska-Lincoln
}

Follow this and additional works at: https://digitalcommons.unl.edu/psychfacpub

Part of the Psychiatry and Psychology Commons

Von Eckardt, Barbara, "Multidisciplinarity and cognitive science" (2001). Faculty Publications, Department of Psychology. 312.

https://digitalcommons.unl.edu/psychfacpub/312

This Article is brought to you for free and open access by the Psychology, Department of at DigitalCommons@University of Nebraska - Lincoln. It has been accepted for inclusion in Faculty Publications, Department of Psychology by an authorized administrator of DigitalCommons@University of Nebraska - Lincoln. 


\title{
Multidisciplinarity and cognitive science
}

\author{
Barbara Von Eckardt*
}

Departments of Philosophy and Psychology, University of Nebraska-Lincoln, Lincoln, NE 68588-0308, USA

\begin{abstract}
The aim of Schunn, Crowley and Okada's (1998) study is to address the question of whether the current state of cognitive science, as represented by Cognitive Science and the Cognitive Science Society, "reflects the multidisciplinary ideals of its foundation." To properly interpret and respond to their results, we need to ask a prior question: What is cognitive science's multidisciplinary ideal? There are at least two conceptions-a "localist" conception, which seems to be implicit in Schunn, Crowley and Okada's discussion, and a "holist" conception. I argue that while both have been endorsed by some cognitive scientists, there are reasons for preferring the holist conception. I then consider what Schunn, Crowley and Okada's findings tell us about the state of cognitive science in light of a holist approach and report on an analysis of the journal's contents which looks at the domain, subdomain, and cognitive capacity investigated. (C) 2001 Cognitive Science Society, Inc. All rights reserved.
\end{abstract}

\section{Introduction}

The aim of Schunn, Crowley and Okada's interesting (Schunn, Rowley \& Okada, 1998) study is to address the question of whether the current state of cognitive science, as represented by Cognitive Science and the Cognitive Science Society, "reflects the multidisciplinary ideals of its foundation" (p. 108). ${ }^{1}$ To properly interpret and respond to their results, we need to ask a prior question: What are cognitive science's multidisciplinary ideals?

* Tel.: +1-402-472-3772.

E-mail address: bvonecka@un1notes.un1.edu (B. Von Eckardt). 


\section{Two conceptions of multidisciplinarity}

There are at least two conceptions which need to be distinguished-a "localist" conception, which seems to be implicit in Schunn, Crowley and Okada's discussion-and a "holist" conception. The localist conception looks like this:

Localist conception of multidisciplinarity:

A field is multidisciplinary if the individual research efforts of its scientists are, typically multidisciplinary.

Individual research efforts can be multidisciplinary in a variety of ways. Following Schunn, Crowley and Okada (1998), these ways can include involving scientists from different disciplines, involving methodologies characteristic of different disciplines, and drawing on research from different disciplines as indicated, for example, by citations.

In contrast to the localist conception of multidisciplinarity, the holist conception takes the focus of multidisciplinarity to be research in the field as a whole rather than individual research efforts.

Holist conception of multidisciplinarity:

A field is multidisciplinary if it is characteristic of the field that multiple disciplines contribute to the execution of its research program.

Clearly, to make this sort of conception work, we need some way of specifying what the research program of a field is and what it means for a discipline to contribute to the execution of that research program. There are undoubtedly several ways of making these notions more precise. I shall adopt the approach spelled out in detail in Von Eckardt (1993).

The key notion of that approach is the notion of a research framework. A research framework belongs to the same class of abstract entities as a Kuhnian paradigm or Lakatos's research "programme"; however, it is better suited for characterizing the commitments of an immature science like cognitive science. (For a detailed argument to this effect, see Von Eckardt, 1993, pp. 345-396.) Specifically, a research framework consists of four sets of elements: a set of assumptions that provide a pretheoretic specification of the domain under study; a set of basic empirical research questions, formulated pretheoretically; a set of substantive assumptions that embody the approach being taken in answering the basic questions and that constrain possible answers to those questions; and a set of methodological assumptions. Given this notion of a research framework, we can characterize the research program of a field as an elaborate and layered set of goals directed at the main goal of answering the basic questions of the field's research framework within the constraints established by the domain, substantive, and methodological assumptions of that research framework. A contribution to the execution of the field's research program will then be any piece of research which furthers this main goal. Finally, we can say that a discipline contributes to the execution of a field's research program insofar as there exist individual research contributions to that program that are authored by a member of that discipline, make use of a methodology characteristic of that discipline, or draw on research belonging to that discipline. Clearly, in this sense, a discipline can, in principle, contribute to a research program via both unidisciplinary and multidisciplinary research. As a result, a field can be multidisciplinary in the holist sense without being multidisciplinary in the localist sense. 
Closely associated with these two conceptions of the multidisciplinarity of a field are two conceptions of what counts as a "real" piece of research for that field. Consider the cognitive science case. Everyone agrees that cognitive science is multidisciplinary. Many would go one step further and say that cognitive science is not just in fact multidisciplinary but essentially multidisciplinary. What implications does this have for what counts as cognitive science research? If one adopts a localist conception, then it is natural to say something like this: A piece of research is "really" cognitive science only if it is multidisciplinary. In contrast, on the holist conception, where the locus of multidisciplinarity is the collective research effort rather than the individual research effort, for cognitive science to be essentially multidisciplinary is for it to be the case that a substantial contribution from every cognitive science discipline is required in order to carry out the cognitive science research program. Hence, for a piece of research to count as "really" cognitive science is simply for that research to contribute to the execution of that research program. In sum, on the localist conception, a piece of research must itself be multidisciplinary to count as "really" cognitive science whereas on the holist conception, both multidisciplinary and unidisciplinary research will count.

\section{The multidisciplinary ideal of cognitive science}

When cognitive scientists embrace a multidisciplinary ideal for cognitive science, which of these senses do they have in mind? That is, what is the multidisciplinary ideal of the cognitive science community? And, what ought it to be ?

One way to approach the descriptive question is to look both at the testimony of experts in the field and at the kinds of research that have been treated as cognitive science research. Using these two kinds of evidence, there are grounds for claiming that both conceptions have been endorsed by (at least some parts of) the cognitive science community.

Let us consider what some of the experts have had to say, looking first at some quotes which suggest support for the localist conception of cognitive science's multidisciplinarity. In the first issue of Cognitive Science, published in January of 1977, Allan Collins, one of the three founding editors, wrote this in his opening editorial:

Unlike psychology or linguistics which are analytic sciences and artificial intelligence which is a synthetic science, cognitive science strives for a balance between analysis and synthesis. (p. 2)

In addition, he summed up his characterization of kinds of articles not appropriate for a journal in cognitive science as "articles that belong exclusively to one of the established disciplines, rather than to cognitive science..." (p. 2). A year later, after describing the various "subdomains" of the six cognitive sciences in a state-of-the-art report to the Sloan Foundation, Ed Walker wrote that it is

the richly articulated pattern of interconnection among these subdomains which makes explicit the basis for the claim that an autonomous science of cognition has arisen in the past decade. . . . Each of the six fields listed is connected to the others by a network of interdisciplinary regiments.... A major concern of this paper is the argument that the network of 
interacting disciplines shown here should be considered as a whole under the name cognitive science. $(\text { p. } 75)^{2}$

A similar point is found in Miller, Polson and Kintsch (1984) when the authors argue that what makes a piece of research "cognitive science research" is simply that it is concerned with intelligence, that it makes use of results or methods characteristic of at least two of the subdisciplines of cognitive science, and that it is produced by researchers who accept the relevance of problems and results from the various other subdisciplines of cognitive science. ${ }^{3}$

Finally, the localist conception of multidisciplinarity seems to be the driving force behind Schunn, Crowley and Okada's (Schunn, Crowley \& Okada, 1998) paper. The "growth of multidisciplinarity" referred to in the title of their article is precisely the growth of multidisciplinary research, that is, research which in some sense involves more than one discipline. In the introduction of their paper they state their aim as examining "the extent to which the current state of cognitive science reflects the multidisciplinary ideals of its foundation" (p. 108). What were those ideals? They write:

$[\mathrm{C}]$ ognitive science is thought to be an emergent discipline in and of itself, rather than just the superset of its constituent disciplines. Cognitive science forums have stated explicitly from the beginning that they place a strong priority on material that is relevant to audiences from numerous disciplines, and that material relevant to only one discipline is inappropriate (e.g., Collins, 1977).... Multidisciplinary fields are thought to arise when members of historically distinct disciplines have something to gain from one another. . . For example, in 1950s, Herbert A. Simon, an economist and political scientist, worked with Allen Newell, a systems researcher with a mathematics background, and Cliff Shaw, an expert programmer, to create a new kind of computer program called Logic Theorist. Their multidisciplinary collaboration not only addressed the immediate concerns of the research project, but also opened up new questions and new methodological possibilities that eventually contributed to the foundation of cognitive science. In many ways, Simon, Newell, and Shaw's collaboration might be considered a canonical example of the power and possibility of multidisciplinary cognitive science research. (my emphasis; p. 108)

They then go on to paraphrase their question in a number of different ways. They are interested in the extent to which "constituent disciplines have merged to form a new discipline" rather than it being the case that cognitive science forums have become places where disciplinary practitioners present disciplinary results to their own disciplinary colleagues. Or, alternatively, their question might be framed thus: have cognitive scientists "integrated new theories and methodologies to form a unique mode of cognitive science research" or have they "simply cited work from other disciplines while continuing to conduct traditional within-discipline research"? Finally, they query whether cognitive scientists are "seeking out multidisciplinary collaborations" or simply "working only with their disciplinary colleagues" (p. 108).

In contrast, a number of cognitive scientists have expressed views about cognitive science that sound more like the holist conception. For example, in the preface to Cognitive Psychology: An Essay in Cognitive Science, Mandler (1985) writes that he hopes to contribute to "constructive bridge building"; yet it seems clear that he regards cognitive psychology research as itself cognitive science research, so long as it is suitably committed to the primary theoretical "foci" of all the cognitive disciplines-representation and process. 
Similarly, Partee, Peters, and Thomason (1985) suggest that the field of cognitive science is best defined by

the research problems that created and continue to animate it. . . Linguistics and psychology are concerned with these issues as they arise in humans, computer science as they arise in machines, and philosophy, logic and artificial intelligence as they arise in humans and machines, and in general. (p. 1)

Finally, the holist conception seems clearly implicit in Flanagan's (Flanagan, 1991) characterization of cognitive science as

not a discipline so much as ... an increasingly well-organized committee of disciplines and subdisciplines, all of which claim to have something to contribute to our understanding of mentality. (p. 177)

Insofar as the holist but not the localist conception sanctions unidisciplinary research as cognitive science research, commitment to the former is also supported by the kinds of research included in various leading compendia of cognitive science research such as Gardner's (1985) The Mind's New Science, Stillings, Feinstein, Garfield, Rissland, Rosenbaum, Weisler, and Baker-Ward's (1987/1998) textbook Cognitive Science: An Introduction, and the four volume An Invitation to Cognitive Science series (Osherson, 1990-98). Each of these describes numerous research projects and studies under the general heading of "cognitive science" and each includes within that category both unidisciplinary and multidisciplinary research. Both the Gardner and Stillings et al. books contain chapters specifically devoted to the contributions made by the principal cognitive science disciplines. And while the first three volumes of the Invitation series are organized topically (volume 1 concerns language, volume 2 is on visual cognition and action, and volume 3 focuses on thinking), within each volume, both unidisciplinary and multidisciplinary research is discussed. For instance, the volume on language contains both chapters on syntax and phonology from a purely linguistic perspective and chapters on speech perception, lexical processing, sentence processing, and language and the brain which draw on work by linguists, psycholinguists, biologists, and neurologists.

Furthermore, despite the fact that Schunn, Crowley and Okada seem to be embracing the localist conception, their findings support the holist conception. The percentage of papers published in Cognitive Science in the three five-year periods sampled by the authors (1979-81, 1984-88, and 1991-95) using a unidisciplinary methodology (specifically, involving either an empirical study only or a simulation only) were $51 \%, 47 \%$, and $56 \%$, respectively.

Clearly, there is, in fact, support within the cognitive science community for both the localist and the holist conception of multidisciplinarity. But which ideal of multidisciplinarity ought we to embrace? I will try to mount an argument in support of holism. The crux of the argument is that we ought to embrace holism and its concomitant more inclusive notion of cognitive science research because it is more rational to do so given what motivated the founding of cognitive science.

It is commonly agreed that cognitive science was founded because researchers from different disciplines-initially, linguistics, artificial intelligence, and psychology-realized, on the one hand, that they were interested in studying roughly the same set of phenomena 


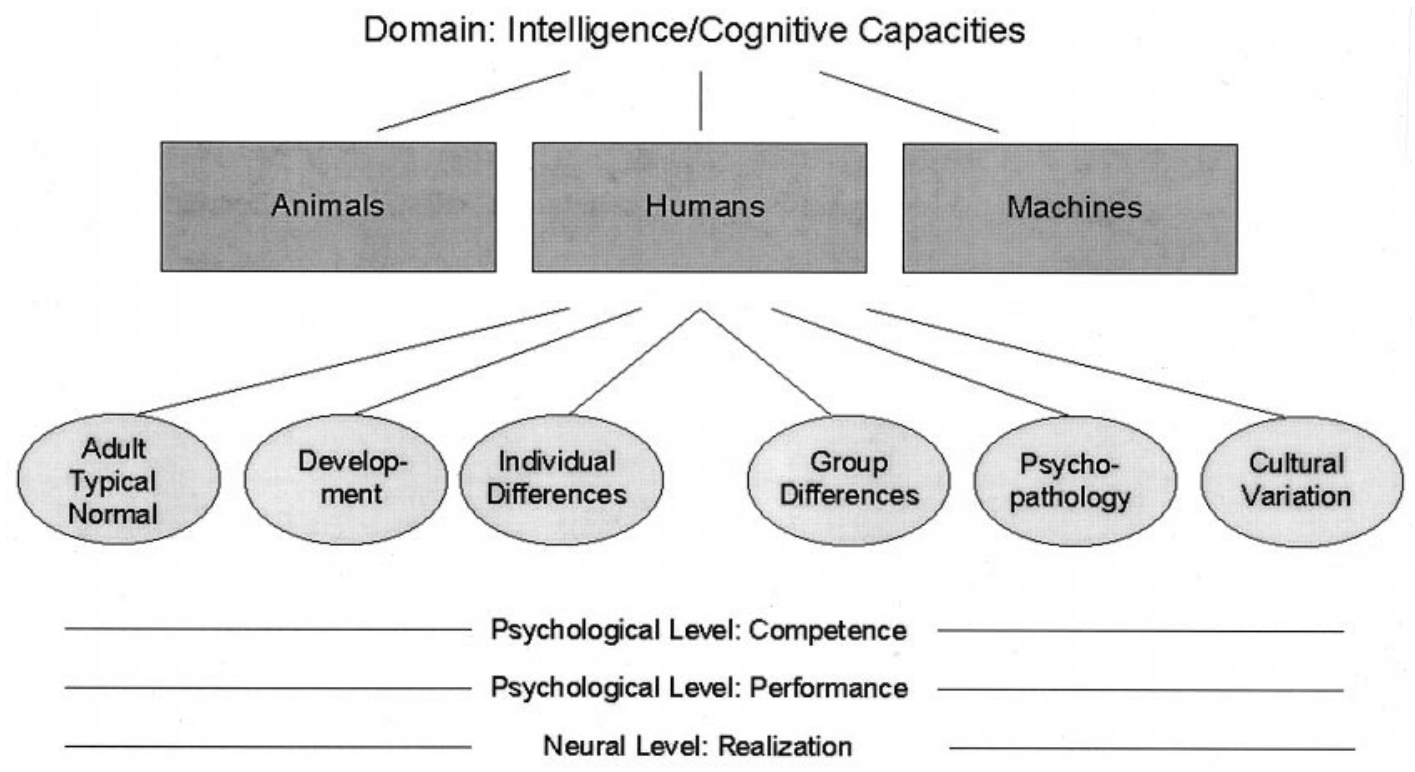

Figure 1. The Structure of the Research Program of Cognitive Science

(namely, intelligence or cognition) using a similar set of theoretical constructs (namely, the notions of representation and computation), and, on the other, that in order to seriously tackle the domain of intelligence/cognition, the points of view and methods of each of their disciplines were required. ${ }^{5}$ In other words, the founders of cognitive science realized that their specific research interests were part of a common research goal, and that to accomplish this goal certain means were required, namely, a multidisciplinary effort.

Let us now look more closely, in the spirit of rational reconstruction, at both the adopted end and the adopted means. The adopted end, on my view, can be best understood as adoption of a certain research program in the sense suggested above. It is important to note, however, that the research program of cognitive science is quite complex, encompassing a number of subsidiary research programs, each focused on a different dimension or aspect of intelligence/cognition. There is, in the first place, the fact that intelligence/cognition is exemplified in three distinct broad domains: humans, machines and animals. Second, in each of these domains, intelligence/cognition can be studied at at least two important levels - the psychological level and the realization level. In humans and animals, of course, the realization level involves the brain. Third, cross-cutting the levels distinction, intelligence/cognition can be studied as it manifests itself in various ways - in the typical, normal adult; in subjects at different points in development; in individuals; in groups (e.g., male/female, novice/ expert); in subjects with psychopathology; and in subjects from different cultures. Fourth, it has become standard to tackle some cognitive capacities from two points of view, often labeled "competence" and "performance." That is, we can look at what any given capacity is, described as an input-output function, and we can look at what is involved in actually executing the capacity. The first of these corresponds to Marr's (Marr, 1982) "computational" level, the second to his "algorithmic" level. (See Fig. 1.) 
Spelling out the research program of cognitive science in this way makes it clear why a multidisciplinary effort is required to carry out the full program: historically, different aspects of that program have been the province of different disciplines. Artificial intelligence focuses on machine intelligence; cognitive psychology looks at the typical normal adult, individual differences, and group differences; developmental psychology concentrates on psychological development; clinical psychologists focus on psychopathology; biology and psychology study animal cognition; anthropology looks at cultural variation; and neuroscience studies the realization of cognition/intelligence in humans and animals. But things get even more complicated than this. For in some cases, a particular kind of cognition (or, more precisely, a particular kind of cognition from certain points of view) is the primary province of a particular discipline. The most obvious example is linguistics, which studies typical normal adult language competence as well as certain aspects of language acquisition. Then there is the fact that different disciplines contribute to cognitive science by bringing a special kind of methodological expertise. Artificial intelligence not only studies machine cognition but excels at developing detailed computational performance models for various capacities at the psychological level. Psychology, in contrast, is particularly expert at securing and analyzing the data necessary to provide empirical support for cognitive theories.

Although, historically, different aspects of the full cognitive science research program have been the province of different disciplines, consideration of that program also makes it clear that, ultimately, more than one discipline will have to be involved in the study of each aspect of the program. The reason for this is that the different dimensions and aspects are all related to one another as parts of the whole; thus, the study of any given dimension or aspect will be constrained by findings from the study of other dimensions and aspects. In some cases, these constraint relations are principled while in other cases they will be merely epistemic. For example, in principle, we cannot arrive at knowledge of how any given capacity is exercised until we know what that capacity is. So, psycholinguistics is constrained by linguistics. Similarly, in principle, we cannot know how human cognition can go wrong unless we know what constitutes normal functioning. Thus, psychopathology is constrained by the study of normal cognition. In contrast, while we can in principle come to know how humans exercise any given capacity without studying how that capacity is realized in the human brain, from an epistemic point of view this is currently not a very smart way to proceed given the relative poverty of purely psychological data. Thus, the study of cognition/ intelligence at the psychological level should take into account the findings of neuroscience.

So, not only is a general multidisciplinary effort necessary for carrying out the cognitive science research program (where many disciplines each do their part), specifically multidisciplinary research (e.g., psycholinguistic or neuropsychological research) is also necessary. Does that mean that we should adopt a localist conception of multidisciplinarity which counts only multidisciplinary research as cognitive science research? Not at all. Here's the argument for holism:

(1) Ceteris paribus, we are interested in maximizing the growth of knowledge in cognitive science. I take it to be self-evident that a scientist in any field will be committed to maximizing the growth of knowledge in his or her field everything else being equal. The latter qualification is important because we can all imagine circumstances (say, 
during times of war) when such maximization would interfere with other overriding goals. But under normal circumstances, when science is not in direct competition for resources with other, possibly more important agendas, being a scientist seems to entail adopting the goals of science as one's own.

(2) Including all research relevant to the cognitive science research program in the production and communal worlds of cognitive science is more likely to increase the growth of knowledge than is including only some. This premise, like the first, doesn't seem to require much justification. According to Schunn, Crowley and Okada (1998), a "disciplinary production world" is one in which "the activities produce something (e.g., books, journals, articles) whereas a "disciplinary communal world" is one in which "the activities focus on the establishment and maintenance of communities of people committed to each other and their shared goals (e.g., departments, societies, etc.)“" (p. 108). The importance of such worlds to the growth of knowledge is, among other things, that they facilitate communication among scientists in any given field. And since science is a communal enterprise, such communication is clearly essential to progress. It then stands to reason that it is better for such worlds to be more rather than less inclusive with respect to research relevant to the pursuit of the intellectual goals of the discipline.

(3) Both multidisciplinary and unidisciplinary research is relevant to pursuit of the cognitive science research program. We have seen that multidisciplinary research is, ultimately, essential to a full understanding of cognition/intelligence because of the existence of constraint relations among claims concerning different dimensions and aspects of cognition/intelligence. Unidisciplinary work is also relevant. In many cases, in fact, it is perfectly legitimate and useful for unidisciplinary work to precede multidisciplinary work. For one thing, some constraint relations are only one way. For example, in general, we do not need to know anything about how a given capacity is exercised in order to know precisely what that capacity is. For another, the state-ofthe-art vis-à-vis the study of one aspect of cognition/intelligence is not always as mature as that of another. Thus, it has only been in recent years that neuroscience has developed techniques for examining questions about neural realization in some detail. And, to my knowledge, virtually nothing is being done to this day to investigate neural realization in people from other cultures. Does this lack of parity mean that the "top-down" psychology of the past few decades was worthless in contributing to the cognitive science research program or that anthropology should be put on hold until neuroscience catches up? Surely not.

Premise 3 is supported by Schunn, Crowley and Okada's own study. For it turns out that in the period 1991-95, 12\% of the studies published in Cognitive Science involved the simulation of pre-existing data. Such simulations were multidisciplinary, of course, but the research which generated the data which the simulations took account of was, typically, unidisciplinary.

(4) Therefore, both multidisciplinary and unidisciplinary research should be included in the production and communal worlds of cognitive science. This subconclusion simply follows from premises $1-3$ 
(5) Adopting a localist conception is associated with excluding unidisciplinary research within the category of cognitive science research, whereas adopting a holist conception is associated with including it. Premise 5 is supported by the earlier discussion of the two conceptions of multidisciplinarity and the two corresponding conceptions of what counts as cognitive science research.

(6) Given subconclusion 4 and premise 5, we ought to adopt the more inclusive conception, namely, holism.

\section{Multidisciplinarity in cognitive science}

Given that what matters to cognitive science is multidisciplinarity of a holist kind, what are we to make of Schunn, Crowley and Okada's (1998) findings? I will restrict myself to those findings that concern patterns of publication in Cognitive Science. Three of their results are of interest. The first speaks to the degree to which each discipline is represented in the journal; the others speak to the extent to which research reported in Cognitive Science is multidisciplinary.

\subsection{Schunn, Crowley and Okada's findings}

Schunn, Crowley and Okada (1998) examined the papers published during three time periods, 1977-81, 1984-88, and 1991-95, with special attention to three measures: (1) the departmental affiliation of the first author, (2) the methodology employed, and (3) the discipline of the literature cited.

\subsubsection{The discipline-representation finding}

"Although there have been minor (and nonsignificant) fluctuations in the relative percentage of psychology and computer science affiliations over the years, these two disciplines have consistently accounted for the majority of first-author affiliations. Authors from linguistics, philosophy, neuroscience, industry, and other fields have been only occasional contributors to cognitive science, and, if anything, are becoming less frequent contributors in recent years .... The only affiliation to change significantly over time is cognitive science itself" (pp. 110-111). The percentages for the most recent period, 1991-95, were 31\% for psychology, $26 \%$ for computer science, $18 \%$ for cognitive science, and $24 \%$ for all the others.

\subsubsection{The methodology finding}

Given the discipline-representation finding, Schunn, Crowley and Okada focused their methodological analysis on the methodologies characteristic of psychology and computer science, namely, empirical study and simulation, respectively. If a study used only one or the other it was classified as "monodisciplinary" (unidisciplinary); if it used both or involved simulation on previously existing data, it was classified as multidisciplinary. The results were as follows: "Over the years, about half of the articles published in Cognitive Science have relied on a monodisciplinary method, presenting either empirical studies only or simulations 
only" (p. 112). However, the number of multidisciplinary studies did almost double from the middle period studied, 1984-88, to the most recent period studied, 1991-95. For 1991-95, $56 \%$ of the articles were unidisciplinary in the above sense, $27 \%$ were multidisciplinary, and $16 \%$ were neither. Further, a comparison with disciplinary journals in psychology and computer science suggested to them that this increase reflects a change in the Cognitive Science Society or cognitive science as a field rather than changes in psychology and computer science.

\subsubsection{The citation finding}

References in articles from three years out of each five-year period were coded by discipline. Schunn, Crowley and Okada gauged disciplinary "influence" by a conservative criterion and a liberal criterion. To satisfy the conservative criterion, at least $25 \%$ of the citations had to be affiliated with a given discipline; to satisfy the liberal criterion, at least 5\% had to be so affiliated. A paper was then judged to be multidisciplinary if two or more disciplines were influential according to either one of the criteria. The results were that "using the conservative criterion $(>25 \%)$, slightly fewer than half of the papers referred to multiple disciplines.... However, using the liberal criterion $(>5 \%)$, almost all papers referred to prior work from multiple disciplines. ... These frequencies of multidisciplinarity did not change over the history of the journal. .." (p. 116). The percentages for multidisciplinary influence for 1991-95 were $45 \%$, on the conservative criterion, and $98 \%$, on the liberal criterion.

\subsection{Interpreting the findings}

In interpreting Schunn, Crowley and Okada's findings, we need to ask two questions: (1) What significance do they have vis-à-vis cognitive science as a field? and (2) what significance do they have with respect to the journal and the Cognitive Science Society?

\subsection{Import for cognitive science}

Depending on which measure one uses, less than a third (on the methodology measure) to less than a half (on the conservative citation measure) of the research published in Cognitive Science is multidisciplinary research. If one adopts a holist conception of what counts as cognitive science research, namely, any research - unidisciplinary or multidisciplinarywhich contributes to the research program of cognitive science, then given that Cognitive Science is one of the few journals in which multidisciplinary research is welcome, it is not unreasonable to suppose that the proportion of multidisciplinary to unidisciplinary work in the field as a whole is much lower than this. Is this fact cause for despair with respect to progress in cognitive science? I don't see why. Half a century is not so very long for a field to be in existence, and given that unidisciplinary work also counts as cognitive science, this sort of proportion may be quite appropriate for the current state of the art. In fact, greater maturity on the part of the component cognitive science disciplines may be necessary before highly fruitful interaction can take place. What is crucial, however, is that we continue to 
remind ourselves of the importance of genuinely interdisciplinary research and work to make our institutions (and reward structures) supportive of such research rather than obstructionist.

What, then, about the discipline-representation finding, namely, the fact that the journal has been almost exclusively dominated by psychology and computer science research? Here also I do not think there is reason for concern with respect to either unidisciplinary or multidisciplinary research when the finding is viewed as an indication of what is happening in the field as a whole. For the results simply don't generalize. If we adopt a holist conception of what constitutes cognitive science research, then clearly there is more unidisciplinary cognitive science research taking place within the cognitive science community as a whole than simply research by psychologists and computer scientists. Such research is occurring in most of linguistics and neuroscience, in significant portions of education and philosophy, and in some areas of anthropology. A similar point can be made with respect to multidisciplinary cognitive science research. If we were to view Schunn, Crowley and Okada's finding as indicative of the field as a whole, we would have to conclude that the vast majority of multidisciplinary research is some combination of psychology and computer science. But this is certainly not the case. Restricting ourselves to the disciplines currently listed in Cognitive Science as the cognitive science disciplines, namely, anthropology, artificial intelligence, education, linguistics, neuroscience, philosophy and psychology, there are 21 possible two-discipline multidisciplinary combinations. Table 1 lists each of these combinations and indicates which has attracted sufficient interest to have associated with it a standard interdisciplinary field label (e.g., "psycholinguistics") and one or more journals. The standard interdisciplinary field labels were determined based on whether there was a corresponding periodical or congress subject heading (e.g., 'Educational anthropology-Periodicals') in the online public access catalog of the University of California at Berkeley Library, a catalog of over eight million books, journals and other materials. Journal titles are current English language journals which come up in a search of the UCB Library periodicals. Out of the 21 possible cross-field combinations, 11 have standard labels and 15 have associated journals. An additional five have labels commonly used in the academic community that aren't UCB categories. Even if we regard only a portion of this cross-field research as cognitive science, it seems clear that work that combines psychology and AI doesn't have a lockhold on multidisciplinary research in the field as a whole.

\subsection{Import for the Cognitive Science Society}

To interpret the significance of Schunn, Crowley and Okada's findings vis-a-vis the Cognitive Science Society, and, especially, the journal Cognitive Science, requires reflection on what we think the aims of the journal and the society are. More specifically, what should their role be in the cognitive science enterprise as a whole? Certainly, the aim of both is to promote the enterprise of cognitive science. But there are special responsibilities which come with the fact that the journal is the only general cognitive science journal. Let me propose four specific aims. The first concerns the journal's role in the production world of cognitive science; the last three, its role in the communal world. 
Table 1

Multidisciplinary combinations with standard labels and examples of current english language journals

\begin{tabular}{ll}
\hline Disciplines & Standard label* \\
\hline Anthropology-Al & \\
Anthropology-Education & educational anthropology \\
Anthropology-Linguistics & (linguistic anthropology)
\end{tabular}

Anthropology-Neuroscience

Anthropology-Philosophy philosophical anthropology (philosophy of anthropology)

Anthropology-Psychology (cognitive anthropology) ethnopsychology cross-cultural psychology

Al-Education

Al-Linguistics

Al-Neuroscience

Al-Philosophy

Al-Psychology

Education-Linguistics

Education-Neuroscience

Education-Philosophy

Education-Psychology

Linguistics-Neuroscience

neurolinguistics

Linguistics-Philosophy computational linguistics

computational neuroscience

(philosophy of Al)

(computational psychology)

language and education

"education-philosophy"

educational psychology
Examples of current English language journals

\section{Taboo}

Anthropology \& education quarterly

American journal of human biology

Human biology

Journal of ethnobiology

Journal of social and biological structures

Anthropology and philosophy

Cross-cultural psychology bulletin

Ethos

Journal of cross-cultural psychology

Psychology and developing societies

Sociologus

American journal of computational linguistics

Bits \& bytes review

Computational linguistics

Computational linguistics and computer

languages

Journal of logic, language, and information

Language and cognitive processes

Languages of design

Mathematical linguistics and automatic

language processing

Computational neuroscience: Trends in research

Cognitive science

Linguistics and education

Educational practice and theory

Journal of philosophy of education

Advances in instructional psychology

The British journal of educational psychology

Communique

Contemporary educational psychology

Educational psychology review

Educational psychology in practice

Educational psychology

Educational psychologist

Journal of behavioral education

Journal of educational psychology

Journal of instructional psychology

School psychology review

Brain and language

Journal of neurolinguistics

Foundations of language

Linguistics and philosophy

Mind \& language

Studies in language 
Table 1 (continued)

\begin{tabular}{|c|c|c|}
\hline Disciplines & Standard label* & Examples of current English language journals \\
\hline Linguistics-Psychology & & $\begin{array}{l}\text { Applied psycholinguistics } \\
\text { International journal of psycholinguistics } \\
\text { Journal of language and social psychology } \\
\text { Journal of verbal learning and verbal behavior } \\
\text { Language and cognitive processes } \\
\text { Linguistics } \\
\text { Mind and language }\end{array}$ \\
\hline Neuroscience-Philosophy & (philosophy of neuroscience) & \\
\hline Neuroscience-Psychology & neuropsychology & $\begin{array}{l}\text { Advances in clinical neuropsychology } \\
\text { Archives of clinical neuropsychology } \\
\text { Behavioral brain research } \\
\text { Behavioral neurology } \\
\text { Brain and cognition } \\
\text { Brain research bulletin } \\
\text { Cognitive neuropsychology } \\
\text { Developmental neuropsychology } \\
\text { The international journal of clinical } \\
\text { neuropsychology } \\
\text { Journal of clinical and experimental } \\
\text { neuropsychology } \\
\text { Journal of cognitive neuroscience } \\
\text { Neuropsychologia } \\
\text { Neuropsychology review } \\
\text { Neuroscience and behavioral physiology }\end{array}$ \\
\hline Philosophy-Psychology & (philosophy of psychology) & $\begin{array}{l}\text { Dialectica } \\
\text { The journal of mind and behavior } \\
\text { Mind and language } \\
\text { Philosophical psychology } \\
\text { Philosophy, psychiatry \& psychology }\end{array}$ \\
\hline
\end{tabular}

* Based on categories of periodicals in the University of California at Berkeley Library online public access catalog. Items in parentheses are labels used in the academic community but not UCB categories.

- To fill in gaps in the production world of cognitive science. On the holist conception of cognitive science research, the production world of cognitive science includes many multidisciplinary and unidisciplinary journals and books. But because Cognitive Science has a special interest in promoting the field of cognitive science, it should make a special effort to publish research for which there is no comfortable fit elsewhere.

- To promote unidisciplinary and multidisciplinary work written for or of special interest to a multidisciplinary audience of cognitive scientists. Even though virtually all cognitive scientists are committed to the multidisciplinarity of cognitive science, few of us have the time and skills necessary to keep up with important findings in all of the various subfields of cognitive science. An important role for Cognitive Science is to effect such cross-disciplinary transfer of information. And this is, in fact, a goal which the editors of the journal have specifically embraced. ${ }^{6}$

- To provide a forum for the exchange of ideas by individuals who identify themselves both as cognitive scientists (in general) and as members of a specific cognitive science discipline. Although there are forums for various of the multidisciplinary combinations 
Table 2

Within each time range, the percentages of journal contributions categorized in exclusive categories according to domain

\begin{tabular}{lccr}
\hline Domain & '78-81 & '84-88 & '91-95 \\
\hline Human alone* & 64 & 82 & 72 \\
Human + machine & 12 & 4 & 6 \\
Human + animal & 1 & 0 & 0 \\
Human + intelligence in general & 1 & 1 & 0 \\
Machine alone & 15 & 6 & 15 \\
Animal alone & 0 & 0 & 0 \\
Intelligence in general alone & 7 & 6 & 8 \\
\hline
\end{tabular}

* Change over time is significant at the .05 level.

that occur within cognitive science, there are very few places where a cognitive scientist (of whatever disciplinary background) can communicate with others who also regard themselves as cognitive scientists. Thus, this must be a special goal of the journal and the society.

- To promote the ideals of cognitive science. Cognitive science is a vast endeavor and each of us can work on only the tiniest piece of the whole project. It is useful to be reminded occasionally of why we have all come to together and to reaffirm our common purpose.

With the above aims in mind, let us turn, once again, to Schunn, Crowley and Okada's findings. As before, given the holist conception of multidisciplinarity, I don't see that the two findings on the extent of multidisciplinary research in the journal are a cause for concern. Unidisciplinary research is also cognitive science research, and the current balance of unidisciplinary and multidisciplinary research seems appropriate given the current state of the art. In contrast, I find the discipline-representation finding more problematic, as apparently do the editors, judging from their commentary (Greeno et al., 1998). But why is it problematic? The superficial answer, of course, is that the journal is not living up to its avowed purpose: it declares itself to be a multidisciplinary journal of seven disciplines and yet, in fact, only two are seriously represented. But there is a deeper reason for concern. The cognitive science research program, as I have sketched it above, is a multifaceted program whose aim is to understand the various aspects and dimensions of intelligence/cognition. But, as I have also noted, different disciplines have primary responsibility for different subresearch programs. As a consequence, if only two of the seven cognitive science disciplines are seriously represented in the journal, it is quite likely that only a small proportion of the total cognitive science research program is being represented.

\subsection{Another study: content focus of research in the journal Cognitive Science}

To test this supposition, I extended Schunn, Crowley and Okada's (1998) study to investigate the content focus of articles during the periods 1977-81, 1984-88 and 1991-95. Unlike Schunn, Crowley and Okada, I looked at both solicited and unsolicited articles, noting, however, in which category an article fell. Like them, I omitted editorials, book 
Table 3

Within each time range, the percentages of journal contributions categorized in basic categories according to domain

\begin{tabular}{lccc}
\hline Domain & '77-81 & '84-88 & '91-95 \\
\hline Human & 69 & 83 & 74 \\
Machine & 23 & 10 & 20 \\
Animal & 1 & 0 & 0 \\
Intelligence in general & 7 & 7 & 8 \\
\hline
\end{tabular}

reviews, comments and responses. I thus gathered data on 75 papers from 1977-81, 79 from 1984-88, and 73 from 1991-95.

The research content focus of each article was categorized in two ways. ${ }^{7}$ First, I looked at the domain or subdomain under investigation. This occurred at two levels. Studies were coded for whether they primarily were investigating the intelligence/cognition of humans, machines, or animals, or intelligence/cognition in general. In addition, for those focused on human intelligence/cognition, I looked at whether the concern was human cognition in general, or some specific aspect of it. Regarding the latter, studies were categorized as dealing with adult normal typical cognition, development, individual differences, group differences, cultural variation, pathology or realization. Second, in addition to the domain under study, I looked at which specific cognitive capacity, if any, was under investigation. Here the options were: general, imaging, intentional action, knowledge, language (either comprehension or production), learning, memory, planning, reasoning, skill acquisition and vision. There was also one study on emotion. A priori, I did not expect the focus on one cognitive capacity rather than another to be tied to discipline in the way that I expected domain focus to be. Nevertheless, it seemed to be something worth looking into.

Tables 2 and 3 show the results of the first analysis. Research on human intelligence/ cognition has dominated the journal by a large margin. Across time periods, $69 \%-83 \%$ of the papers have focused on humans, and $10 \%-23 \%$ focused on machines. Animals have received virtually no attention and the study of some aspect of intelligence in general has held steady at $7 \%-8 \%$.

Table 4 shows the breakdown for papers dealing with human intelligence/cognition. It is

Table 4

Within each time range, the percentages of journal contributions on human cognition categorized in basic categories according to subdomain

\begin{tabular}{lccc}
\hline Subdomain & '77-81 & '84-88 & '91-95 \\
\hline Adult normal typical cognition & 65 & 76 & 65 \\
Cultural variation & 1 & 0 & 0 \\
Development & 8 & 8 & 5 \\
General & 3 & 1 & 1 \\
Group differences & 3 & 1 & 4 \\
Individual differences & 0 & 0 & 0 \\
Pathology & 1 & 1 & 1 \\
Realization & 1 & 0 & 0 \\
\hline
\end{tabular}


Table 5

Within each time range, the percentages of journal contributions on human cognition categorized according to capacity studied

\begin{tabular}{lccc}
\hline Capacity studied & '77-81 & '84-88 & '91-95 \\
\hline Emotion & 0 & 2 & 0 \\
General & 13 & 6 & 5 \\
Imagery & 5 & 0 & 2 \\
Intentional action & 2 & 0 & 0 \\
Knowledge & 13 & 16 & 13 \\
Language & 38 & 28 & 23 \\
Learning* & 2 & 9 & 15 \\
Memory & 4 & 6 & 2 \\
Planning & 4 & 23 & 2 \\
Reasoning & 24 & 5 & 37 \\
Skill acquisition & 2 & 3 & 0 \\
Vision & 2 & & 5 \\
\hline
\end{tabular}

* Change over time is significant at the .05 level.

here that the effects of the dominant representation by psychologists (specifically, cognitive psychologists) and computer scientists in the journal can be seen. The primary focus $(65 \%-76 \%)$ has been on the study of adult normal typical cognition for all three time periods. The study of development is next, with between $5 \%$ and $8 \%$. Four percentage or less of the papers have been on group differences (almost exclusively the study of experts vs. novices), a very small number on cultural variation, pathology, and realization, and none on individual differences. There have been no significant changes in these proportions over time.

Finally, Table 5 shows that not all of cognition/intelligence has received equal attention. Researchers have paid the most attention to language $(23 \%-38 \%)$ and reasoning $(23 \%-$ $38 \%)$, with knowledge (13\%-16\%) and learning (2\%-15\%) next in line. All the rest - emotion, imagery, intentional action, memory, planning, skill acquisition, and visioneach represent less than $6 \%$. The only significant change over time is with respect to learning (from $2 \%$ in $1977-81$ to $15 \%$ in 1991-95), a trend which is almost certainly due to the growing interest in connectionist modeling.

\section{Conclusion}

In the conclusion of their paper, Schunn, Crowley and Okada express the hope that their data "may be used to support productive dialog[ue] regarding the development of the Cognitive Science Society and the discipline of cognitive science itself" (p. 128). My aim has been to engage in precisely such dialogue. I have suggested that any concern with the multidisciplinarity of cognitive science must begin with a consideration of what it means for a field to be multidisciplinary and what the ideal of multidisciplinarity for cognitive science, in particular, is and should be. I have argued that many cognitive scientists, in fact, do, and moreover should, embrace a holist conception of multidisciplinarity. On this conception, which counts both unidisciplinary and multidisciplinary research as equally parts of cogni- 
tive science, Schunn, Crowley and Okada's data are less disheartening than on a localist conception-especially with respect to the field as a whole. Cognitive science is still alive and well despite the fact that much of what counts as cognitive science research still comes in disciplinary guise. Similarly, we should not despair over the current balance of uni- and multidisciplinary work in the journal Cognitive Science. In contrast, the lack of representation of five out of the seven official cognitive science disciplines is a matter of concern, not only because it flies in the face of the journal's subtitle, but, more importantly, because it is quite likely responsible for the lack of attention in the journal to many important areas of cognitive science, including a major portion of its domain (e.g., the study of animal cognition/intelligence), many of the subdomains within the study of human cognition/ intelligence (e.g., cultural variation, development, individual differences, pathology and realization), and many specific capacities (e.g., imagery, intentional action, memory, planning, skill acquisition and perception). There are, of course, other more disciplinary venues where these areas are reported on, but given that Cognitive Science seeks to promote the cross-disciplinary transfer of information so vital to the field, the editors' renewed resolve (in Greeno et al., 1998) to encourage "the strongest representation of all of the disciplines of cognitive science in the journal and the Society meetings that we can achieve" should be applauded and supported by all of us who believe that cognitive science is an important enterprise.

\section{Notes}

1. A more recent version of this work can be found in Schunn et al. (forthcoming).

2. Walker (1978). Page reference is to a partial reprinting of the Walker report in Machlup and Mansfield (1983).

3. Miller, Polson and Kintsch (1984), pp. 16-17.

4. I dwell on this point since several readers of this paper have questioned my contention that Schunn, Crowley, and Okada have a localist conception of multidisciplinarity in mind. A further piece of evidence in favor of my interpretation is an e-mail I received from Christian Schunn to whom I sent a copy of the paper. He there writes that he agrees that there is a larger sense of multidisciplinarity that their measures did not tap and worries about how one would measure holist multidisciplinarity.

5. See Stillings et al. (1987/1998), p. 1.

6. The "Information for Authors" section states that "research reports which are specifically written for a multidisciplinary audience are given the highest priority."

7. Since the categorizations involved were so straight-forward, no inter-rater reliability test was performed.

\section{References}

Collins, A. (1977). Why cognitive science? Cognitive Science, 1, 1-12.

Flanagan, O. (1991). The Science of Mind (Second edition). Cambridge, Massachusetts: The MIT Press. 
Gardner, H. (1985). The Mind's New Science: A History of the Cognitive Revolution. New York: Basic Books, Inc.

Greeno, J., Clancey, W., Lewis, C., Seidenberg, M., Derry, S., Morton, A., Langley, P., Shafto, M., Gentner, D., Lesgold, A., \& Seifert, C. (1998). Efforts to encourage multidisciplinarity in the Cognitive Science Society. Cognitive Science, 22(1), 131-132.

Machlup, F., \& Mansfield, U. (Eds.). (1983). The study of information: Interdisciplimary messages. NY: John Wiley \& Sons.

Mandler, G. (1985). Cognitive psychology: An essay in cognitive science. Hillsdale, N.J.: Erlbaum Associates.

Marr, D. (1982). Vision. San Francisco: Freeman

Miller, J., Polson, P., \& Kintsch, W. (1984). Problems of methodology in cognitive science. In W. Kintsch, J. Miller \& P. Polson (Eds.), Methods and tactics in cognitive science, (pp. 1-18). Hillsdale, NJ: Erlbaum.

Osherson, D. N. (Gen. Ed.). (1990-1998). An invitation to cognitive science. 4 volumes. Cambridge, MA: The MIT Press.

Partee, B., Peters, S., \& Thomason, R. (1985). Overview and recommendations. In B. H. Partee, S. Peters \& R. Thomason (Eds.), Report of Workshop on Information and Representation, Workshop on Information and Representation. Washington, D.C.

Schunn, C., Crowley, K., \& Okada, T. (1998). The growth of multidisciplinarity in the Cognitive Science Society. Cognitive Science, 22(1), 107-130.

Schunn, C., Crowley, K., \& Okada, T. (forthcoming). Cognitive science: Interdisciplinarity now and then. In S.J. Derry \& M.A. Gernsbacher (Eds.), Problems and promises of interdisciplinary collaboration: Perspectives from cognitive science. Mahwah, $\mathrm{NJ}$ : Erlbaum.

Stillings, N., Feinstein, M. H., Garfield, J. L., Rissland, E. L., Rosenbaum, D. A., Weisler, S., \& Baker-Ward, L. (1987/1998). Cognitive science: An introduction. Cambridge, Massachusetts: The MIT Press.

Von Eckardt, B. (1993). What is cognitive science? Cambridge, Massachusetts: The MIT Press.

Walker, E., (Ed.). (1978). The Alfred P. Sloan Foundation state of the art report. 